\title{
Targeted mutation of plasma phospholipid transfer protein gene markedly reduces high-density lipoprotein levels
}

\author{
Xian-cheng Jiang, ${ }^{1}$ Can Bruce, ${ }^{1}$ Jefferson Mar, ${ }^{1}$ Min Lin, ${ }^{1}$ Yong Ji, ${ }^{1}$ Omar L. Francone, ${ }^{2}$ \\ and Alan R. Tall ${ }^{1}$ \\ ${ }^{1}$ Division of Molecular Medicine, Department of Medicine, Columbia University, New York, New York 10032, USA \\ ${ }^{2}$ Central Research Division, Department of Cardiovascular and Metabolic Diseases, Pfizer Inc., Groton, Connecticut 06340, USA
}

Address correspondence to: Xian-cheng Jiang, Division of Molecular Medicine, Department of Medicine, Columbia University, 630 West 168th Street, New York, New York 10032, USA. Phone: (212) 305-7720; Fax: (212) 305-5052; E-mail: xcj1@columbia.edu

Received for publication October 21, 1998, and accepted in revised form January 26, 1999.

\begin{abstract}
It has been proposed that the plasma phospholipid transfer protein (PLTP) facilitates the transfer of phospholipids and cholesterol from triglyceride-rich lipoproteins (TRL) into high-density lipoproteins (HDL). To evaluate the in vivo role of PLTP in lipoprotein metabolism, we used homologous recombination in embryonic stem cells and produced mice with no PLTP gene expression. Analysis of plasma of F2 homozygous PLTP $^{-/-}$mice showed complete loss of phosphatidylcholine, phosphatidylethanolamine, phosphatidylinositol, sphingomyelin, and partial loss of free cholesterol transfer activities. Moreover, the in vivo transfer of $\left[{ }^{3} \mathrm{H}\right] \mathrm{phosphatidylcholine} \mathrm{ether} \mathrm{from} \mathrm{very-low-density} \mathrm{proteins} \mathrm{(VLDL)} \mathrm{to} \mathrm{HDL} \mathrm{was} \mathrm{abolished} \mathrm{in}$ PLTP $^{-/-}$mice. On a chow diet, PLTP ${ }^{-/-}$mice showed marked decreases in HDL phospholipid (60\%), cholesterol (65\%), and apo AI (85\%), but no significant change in non-HDL lipid or apo B levels, compared with wild-type littermates. On a high-fat diet, HDL levels were similarly decreased, but there was also an increase in VLDL and LDL phospholipids (210\%), free cholesterol (60\%), and cholesteryl ester (40\%) without change in apo B levels, suggesting accumulation of surface components of TRL. Vesicular lipoproteins were shown by negative-stain electron microscopy of the free cholesterol- and phospholipid-enriched IDL/LDL fraction. Thus, PLTP is the major factor facilitating transfer of VLDL phospholipid into HDL. Reduced plasma PLTP activity causes markedly decreased HDL lipid and apoprotein, demonstrating the importance of transfer of surface components of TRL in the maintenance of HDL levels. Vesicular lipoproteins accumulating in PLTP $^{-/-}$mice on a high-fat diet could influence the development of atherosclerosis.
\end{abstract}

J. Clin. Invest. 103:907-914 (1999).

\section{Introduction}

The inverse relationship between high-density lipoprotein (HDL) levels and coronary heart disease (1) has stimulated research on HDL's metabolic origins. Havel and colleagues $(2,3)$ initially suggested that there may be transfer of surface components (phospholipids, soluble apolipoproteins) from triglyceride-rich lipoproteins (TRL) into HDL. This was subsequently demonstrated by injection or perfusion of chylomicrons or very-low-density lipoproteins (VLDL) in intact rats or their organs (4-7). In addition to its origin from TRL, nascent HDL was also found in mesenteric lymph and hepatic perfusates, where it may arise as a result of the interaction of cellular plasma membranes with small intestine- and liver-secreted apo AI (8-11). Thus, HDL may be derived from various sources, and the quantitative importance of surface transfer processes in the formation of HDL has never been determined.

The mode of incorporation of phospholipids of TRL into HDL may involve the formation of discrete lamellar HDL particles that can be converted into spherical HDL by the action of plasma lecithin: cholesterol acyltransferase $(11,12)$ or incorporation of phospholipid into preexisting HDL by collision or aqueous diffusion $(12,14$, $15)$. However, Tall and colleagues $(16,17)$ characterized a novel plasma phospholipid transfer activity and showed that it stimulated the transfer and exchange of phospholipids between VLDL and HDL. Subsequently, phospholipid transfer protein (PLTP) was purified, cloned, and found to belong to a gene family of lipid transfer/lipopolysaccharide-binding proteins $(18,19)$. Studies of plasma from subjects with homozygous null mutations of their cholesteryl ester transfer protein gene suggested that about half of the plasma phospholipid exchange activity is due to cholesteryl ester transfer protein (CETP), and the other half is due to PLTP (20). However, recent work (21) has suggested that the related lipopolysaccharide-binding protein might also contribute significantly to plasma phosphatidylcholine (PC) and phosphatidylinositol (PI) transfer activities.

The mouse is an excellent model to study the role of PLTP, because this species lacks significant CETP activity and possesses abundant plasma phospholipid transfer activity (22). However, overexpression of PLTP in the mouse has led to conflicting results (23-25). To determine the contribution of the PLTP gene to plasma phospholipid transfer activities and lipoprotein levels, we have prepared PLTP gene knockout mice.

\footnotetext{
Methods

Construction of gene replacement vector. The overall strategy for gene targeting was to replace intron 1, exon 2, and part of intron 2 with the neomycin-resistant gene (Fig. 1). Because exon 2 contains the translation initiation codon, ATG, as well as the signal peptide and the first 16 amino acids of mature PLTP, deletion of
} 
exon 2 would be expected to create a null PLTP mouse model. The short arm $(530 \mathrm{bp})$ and long $\operatorname{arm}(5.2 \mathrm{kbp})$ of the targeting vector were prepared from genomic DNA by PCR using two pair of primers: 5'-CCACGTGACCACACTACTAAG-3'(located in first exon), $5^{\prime}$-TGGTCATGCAACTAGAACGG-3' (located in the end of intron 1); and 5'-GGGACCTGAGTGTCTCCATG-3' (located in intron 2), 5'-CGGAATTCCATCTCGAGGTTGCCGT-3' (located in intron 6), respectively. Embryonic stem (ES) cells were electroporated by PacI-linearized targeting vector and screened by sequential selection with G418 and Ganciclovir (26, 27). Southern blot analysis and PCR were used for screening the targeted ES cells. Genomic DNA was digested with EcoRI and a 300 -bp DNA fragment, just $5^{\prime}$ to the targeting vector (Fig. 1), was used as a probe for Southern blots. Two primers, one located outside of targeting vector and the other at the $3^{\prime}$ end of the neomycin-resistant gene (Fig.1), were also used to perform PCR. Four positive clones were identified out of 196 screened and were injected into blastocysts. Chimeric males were mated with C57BL/ 6 females, and the resulting F1 mice containing the disrupted allele were intercrossed to generate F2 mice.

Animals and diets used in this study. All phenotypic characterizations were performed with wild-type $(+/+)$, heterozygous $(+/-)$, and homozygous (-/-) littermates of the F2 generation, 10-12 weeks old. Two diets were used: Purina Rodent Chow (no. 5001) and no. 5001 with $20 \%$ hydrogenated coconut oil and $0.15 \%$ cholesterol (Research Diets Inc., New Brunswick, New Jersey, USA).

Northern blotting and RNase protection assay. For PLTP mRNA Northern blotting, poly $(\mathrm{A})^{+} \mathrm{RNA}(2 \mu \mathrm{g})$ from lung was analyzed, using a mouse PLTP cDNA (666 bp, nucleotides 3-669) as a probe, and a mouse PLTP mRNA RNase protection assay was performed as described (22).

Lipid transfer assays. Egg PC $(10 \mu \mathrm{mol})$ containing $10 \mathrm{nmol}$ of $\left[{ }^{3} \mathrm{H}\right] \mathrm{PC}$ (L-a-dipalmitoyl-[2-palmitoyl-9, $\left.10-{ }^{3} \mathrm{H}(N)\right]$-phosphatidylcholine) or $\left[{ }^{14} \mathrm{C}\right]$ phosphatidylethanolamine (L- $\alpha-1-$ palmitoyl, 2-arachidonyl-[arachidonyl-1- $\left.{ }^{14} \mathrm{C}\right]$-phosphatidylethanolamine) or $\left[{ }^{3} \mathrm{H}\right]$ phosphatidylinositol (L- $\alpha$ - $[$ myoinositol-2- $\left.{ }^{3} \mathrm{H}(N)\right]$-phosphatidylinositol) or $\left[{ }^{3} \mathrm{H}\right]$ sphingomyelin ( $N$-palmitoyl-9, $10-{ }^{3} \mathrm{H}$-sphingomyelin) was dried under a stream of nitrogen, resuspended in $1 \mathrm{ml}$ of a solution of $10 \mathrm{mM}$ Tris, $150 \mathrm{mM} \mathrm{NaCl}, 1 \mathrm{mM}$ EDTA ( $\mathrm{pH} 7.4$ ), and then probe-sonicated and centrifuged. Transfer of radiolabeled phospholipid was measured by incubating $3 \mu \mathrm{l}$ of plasma with radiolabeled phospholipid vesicles (125 nmol PC) and HDL ( $250 \mu \mathrm{g}$ protein) in a final volume of $400 \mu \mathrm{l}$ at $37^{\circ} \mathrm{C}$ for $1 \mathrm{~h}$. Vesicles were subsequently precipitated by the addition of $300 \mu \mathrm{l}$ of a solution of $500 \mathrm{mM} \mathrm{NaCl}, 215 \mathrm{mM} \mathrm{MnCl}_{2}$, $445 \mathrm{U} / \mathrm{ml}$ heparin, and the radioactivity of a $500-\mu \mathrm{l}$ aliquot of the supernatant was measured (25).

To measure $\left[{ }^{3} \mathrm{H}\right]$ cholesterol transfer, $3 \mu$ lof plasma was incubated for $1 \mathrm{~h}$ at $37^{\circ} \mathrm{C}$ with $\mathrm{PC} /\left[{ }^{3} \mathrm{H}\right]$ cholesterol vesicles $(125$ $\mathrm{nmol}$ of PC) and isolated human HDL ( $250 \mu \mathrm{g}$ of protein $)$ in a final volume of $400 \mu 1$. After incubation, PC vesicles were selectively precipitated, and radioactivity in the supernatant was measured. All values are means \pm SD based on analyses of individual mouse plasma and represent of 6-10 animals per group.

Lipoprotein turnover. Plasma VLDL was labeled with $\left[{ }^{3} \mathrm{H}\right]$ dipalmitoylphosphatidylcholine (DPPC) ether as described previously (28). Mice were injected intravenously (femoral vein) with $\left[{ }^{3} \mathrm{H}\right] \mathrm{DPPC}$ ether-labeled VLDL, 7.5-9.5 $\times 10^{5} \mathrm{cpm}$. Blood $(70 \mu \mathrm{l})$ was taken from the tail vein at different times. VLDL and LDL were precipitated using an HDL cholesterol reagent (Sigma Chemical Co., St. Louis, Missouri, USA) and the radioactivity in supernatant, representing $\left[{ }^{3} \mathrm{H}\right] \mathrm{DPPC}$ ether transferred from VLDL to HDL, was measured.

Lipid and lipoprotein assays. For small volumes of mouse plasma, HDL was separated from apo B-containing lipoproteins by using an HDL cholesterol reagent (Sigma Chemical Co.). The total cholesterol and phospholipids in plasma and HDL were assayed by enzymatic methods (Wako Pure Chemical Industries Ltd., Osaka, Japan). Lipoprotein profiles were obtained by fast protein liquid chromatography (FPLC), using two Sepharose 6B columns (29).

Quantitation of HDL subspecies. The proportion of pre- $\beta$ and $\alpha$ electrophoretic mobility HDL species in the PLTP knockout and wildtype mice was determined as described previously (23).

Electron microscopy. Negative-stain electron microscopy was done using a JEM-1200 EX II electron microscope (JEOL USA Inc., Cranford, New Jersey, USA). Lipoprotein samples in $125 \mathrm{mM}$ ammonium acetate, $2.6 \mathrm{mM}$ ammonium carbonate, and $0.26 \mathrm{mM}$ EDTA ( $\mathrm{pH} 7.4$ ) were mixed with an equal volume of $2 \%$ sodium phosphotungstate ( $\mathrm{pH} 7.4$ ) on a carbon/Formvar-coated copper grid (Electron Microscopy Sciences, Fort Washington, Pennsylvania, USA). After $30 \mathrm{~s}$, the excess liquid was blotted, the rest was allowed to dry, and the grid was examined within $1 \mathrm{~h}$.

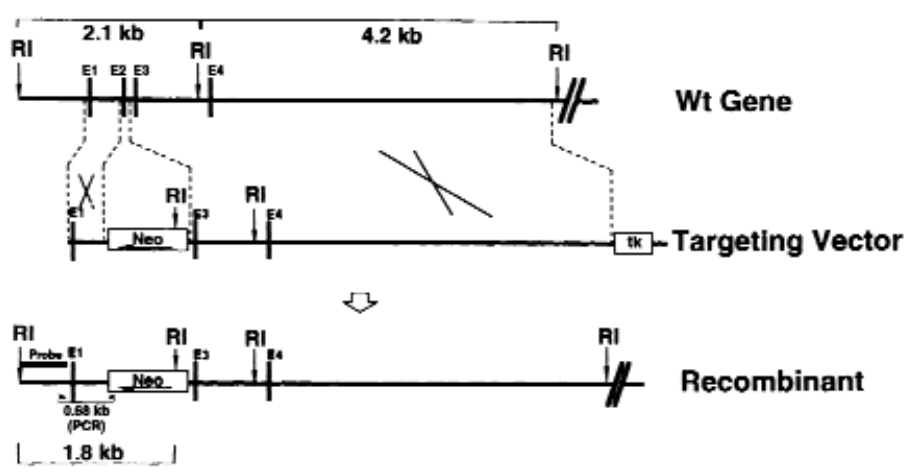

b

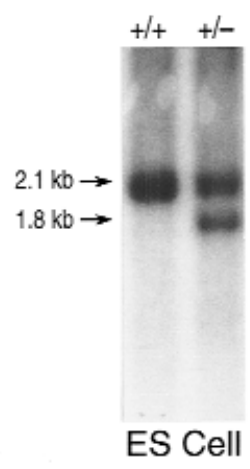

c

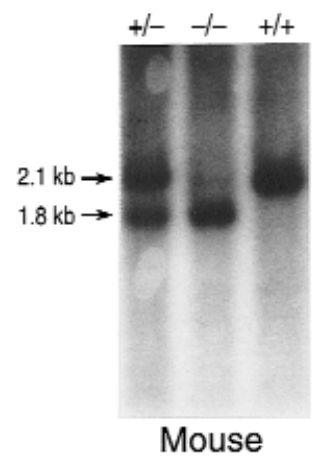

Figure 1

Strategy used to disrupt the mouse PLTP gene. (a) The top line represents the map of the endogenous murine PLTP gene and its flanking sequence. The middle line represents the vector used to target the PLTP locus. The bottom line shows the predicted organization of the locus after homologous recombination. A probe and a pair of PCR primers indicated in this line were used to confirm the integrity of site-specific integration. (b) Southern blot analysis of ES cells and $(\boldsymbol{c})$ mouse tail-tip genomic DNA, respectively, digested with EcoRI and hybridized with the probe. Normal ES cell DNA and control mice DNA with 2.1$\mathrm{kb}$ signal only $(+/+)$; targeted ES cell DNA and heterozygous deficient mice with $2.1-\mathrm{kb}$ and $1.8-\mathrm{kb}$ signal $(+/-)$; homozygous deficient mice with $1.8-\mathrm{kb}$ signal only $(-/-)$. ES, embryonic stem; neo, neomycin-resistant gene; PLTP, phospholipid transfer protein; $t K$, herpes simplex virus thymidine kinase gene. 
Figure 2

PLTP mRNA measurement. (a) Northern blot of poly $(A)^{+}$RNA $(2 \mu \mathrm{g})$ from lung probed with a mouse PLTP cDNA (666 bp, nucleotides 3-669). (b) RNase protection analysis of mouse tissues. A fragment of the mouse PLTP cDNA (160 bp, codons 750-910) was cloned into Bluescript KS+ (Stratagene, La Jolla, California, USA) and used to prepare radiolabeled cRNA probes; $30 \mu \mathrm{g}$ of total RNA was used in the assay.

\section{Results}

Creation of a PLTP-deficient mouse. We used positive and negative selection to target the PLTP gene, replacing exon 2 (containing the translation start site) with a neo gene (Fig. 1a). To screen for homologous integrants, genomic DNA from ES cells was digested with EcoRI, and a $5^{\prime}$ PLTP flanking probe was used to analyze Southern blots (Fig. 1b), revealing homologous integration in 4 out of 196 ES cell clones. The addition of a $1.8-\mathrm{kb}$ signal to the endogenous $2.1-\mathrm{kb}$ signal indicated site-specific integration at the PLTP locus. The correctly targeted cells were then injected into C57BL/6J host blastocysts. Fifteen chimeras were generated (12 male, 3 female), and eight of the resulting males transmitted the disrupted PLTP allele through the germline. The resulting heterozygous mice were crossed, and the targeted allele was segregated in a Mendelian fashion. Of 96 progeny analyzed from heterozygous crosses by Southern blotting of tail-tip DNA, 25 (26\%) of the progeny were wild-type, 51 (53\%) heterozygous, and 20 (21\%) homozygous for the disrupted allele (Fig. 1c). Homozygous crosses yielded viable progeny.

A Northern blot of RNA prepared from mouse lung was probed with a mouse PLTP cDNA probe ( $666 \mathrm{bp}$ of $5^{\prime}$ end) and showed that there was no $1.7-\mathrm{kb}$ PLTP message in homozygous deficient animals $\left(\mathrm{PLTP}^{-/}\right)$and that there was a reduction of the message in heterozygous deficient animals $\left(\right.$ PLTP $\left.^{+/-}\right)$(Fig. $2 a$ ). RNase protection assay of RNA prepared from mouse lung and liver, two of the major sites

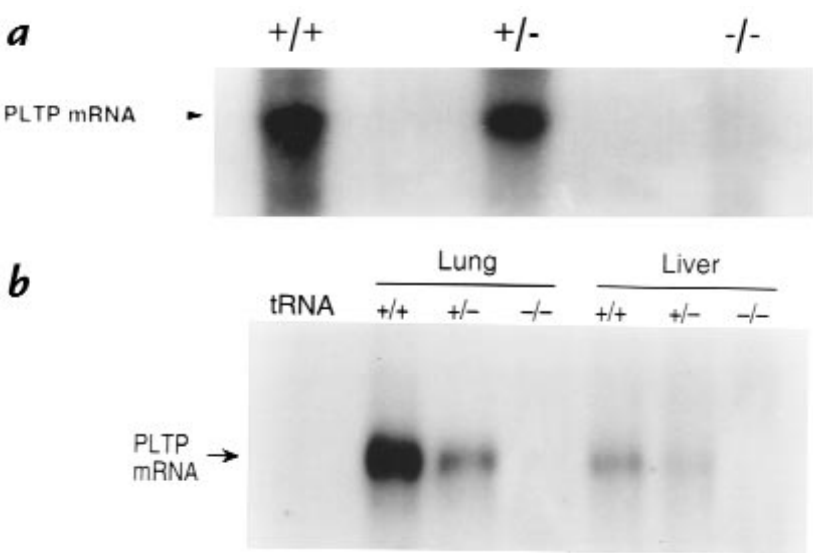

of PLTP gene expression, confirmed that there was no PLTP mRNA in homozygous deficient animals (Fig. 2b).

Plasma and in vivo lipid transfer activity. Plasma PLTP activity analysis using $\left[{ }^{3} \mathrm{H}\right]$ phosphatidylcholine $(\mathrm{PC})$ vesicles as donor and HDL as acceptor showed no PC transfer activity in PLTP $^{-/-}$mice (Fig. 3a). There was $\sim 60 \%$ residual activity in $\mathrm{PLTP}^{+/-}$mice (Fig. 3a). Moreover, in $\mathrm{PLTP}^{-/-}$mice, there was no plasma phosphatidylethanolamine (PE), phosphatidylinositol (PI), or sphingomyelin (SM) transfer activity (Fig. $3 a$ ). Using mixed PC/ $\left[{ }^{3} \mathrm{H}\right]$ cholesterol vesicles as donor, there was also a marked decrease in the ability of plasma to stimulate the transfer of free cholesterol radioactivity into HDL (Fig. 3a).

Next, we evaluated the in vivo transfer of phospholipids between plasma lipoproteins. VLDL containing the nondegradable $\mathrm{PC}$ analogue $\left[{ }^{3} \mathrm{H}\right] \mathrm{PC}$ ether was injected intravenously. In wild-type mice, there was a rapid transfer of a substantial portion of PC ether radioactivity into HDL. In contrast, $\left[{ }^{3} \mathrm{H}\right] \mathrm{PC}$ ether transfer from VLDL to HDL was almost absent in PLTP $^{-/-}$mice (Fig. 3b).

Plasma lipoprotein analysis. As indicated in Table 1, plasma lipoprotein analysis by precipitation (F2 $\mathrm{PLTP}^{-/-}$ mice versus wild-type littermates) showed marked reduction in HDL phospholipid, cholesteryl ester, and free cholesterol $(63 \%, 64 \%$, and $66 \%$, respectively, for male; $66 \%, 69 \%$, and $70 \%$, respectively, for female). NonHDL lipids were not significantly altered. Heterozygous $\left(\mathrm{PLTP}^{+/-}\right)$mice showed no significant changes in their lipid and lipoprotein levels (Table 1).

Table 1

Plasma and lipoprotein lipid analysis in wild-type $(+/+), \mathrm{PLTP}^{+/-}$, and PLTP-/- mice on a chow diet

\begin{tabular}{|c|c|c|c|c|c|c|c|c|}
\hline PL & HDL-PL & VLDL/LDL-PL & Cholesterol & $\begin{array}{r}\text { HDL-CE } \\
(\mathrm{mg} / \mathrm{dl})\end{array}$ & HDL-FC & VLDL/LDL-C & Apo B & TG \\
\hline $165 \pm 24$ & $121 \pm 22$ & $43 \pm 9$ & $101 \pm 26$ & $70 \pm 9$ & $9 \pm 5$ & $22 \pm 7$ & $58 \pm 13$ & $59 \pm 9$ \\
\hline $150 \pm 25$ & $111 \pm 13$ & $39 \pm 12$ & $90 \pm 28$ & $62 \pm 17$ & $8 \pm 4$ & $20 \pm 9$ & $56 \pm 9$ & $63 \pm 7$ \\
\hline $81 \pm 27^{A}$ & $45 \pm 21^{A}$ & $36 \pm 15$ & $45 \pm 11^{\mathrm{A}}$ & $25 \pm 15^{\mathrm{A}}$ & $3 \pm 1^{\mathrm{A}}$ & $17 \pm 8$ & $49 \pm 15$ & $64 \pm 9$ \\
\hline $112 \pm 19$ & $77 \pm 10$ & $35 \pm 8$ & $99 \pm 15$ & $71 \pm 11$ & $10 \pm 6$ & $18 \pm 5$ & $56 \pm 12$ & $53 \pm 8$ \\
\hline $108 \pm 12$ & $74 \pm 20$ & $34 \pm 10$ & $93 \pm 23$ & $69 \pm 21$ & $8 \pm 5$ & $16 \pm 6$ & $54 \pm 11$ & $56 \pm 9$ \\
\hline $51 \pm 11^{\mathrm{A}}$ & $26 \pm 8^{\mathrm{A}}$ & $26 \pm 9$ & $36 \pm 15^{A}$ & $22 \pm 13^{\mathrm{A}}$ & $3 \pm 2^{A}$ & $12 \pm 7$ & $51 \pm 15$ & $59 \pm 6$ \\
\hline
\end{tabular}

HDL was separated from VLDL/LDL by precipitation with HDL cholesterol reagent. The total cholesterol, phospholipid, and triglyceride concentrations were determined by enzymatic methods. ApoB, including apoB48 and apoB100, was measured by ELISA as described (39). APLTP knockout mice versus wild-type mice, $P<0.001$. Values are means \pm SD based on analyses of individual mouse plasma and represent 6-10 animals per group. $C$, cholesterol; $C E$, cholesteryl ester; FC, free cholesterol; HDL, high-density lipoprotein; $L D L$, low-density lipoprotein; PL, phospholipid; PLTP, phospholipid transfer protein; TG, triglyceride; VLDL, very-low-density lipoprotein. 
$a$

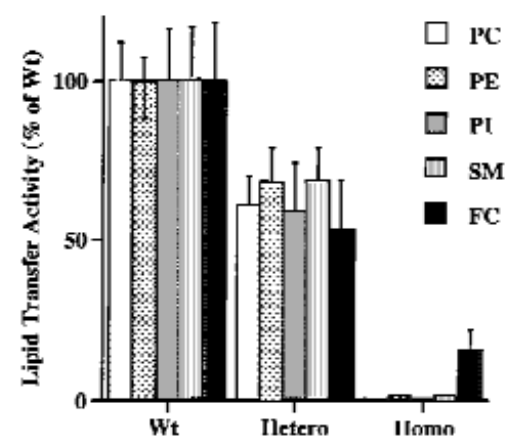

$\boldsymbol{b}$

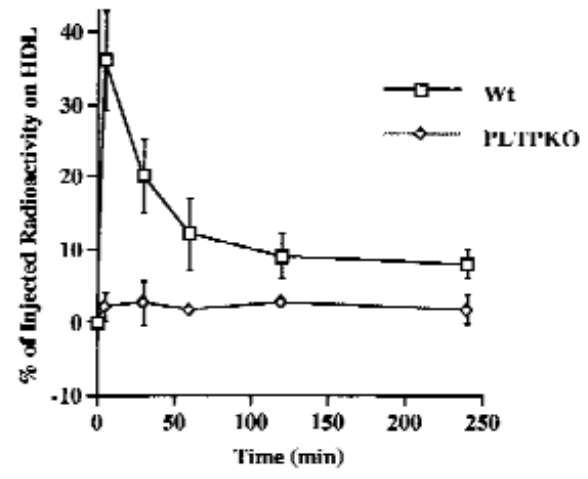

Figure 3

PLTP activity assays. (a) In vitro assays using mouse plasma. Transfer of radiolabeled lipids from vesicles into HDL was measured as described in Methods. Values are means \pm SD based on analyses of individual mouse plasma (6-10 animals per group). (b) In vivo transfer of phospholipids from VLDL into HDL. Mice were injected intravenously (femoral vein) with $\left[{ }^{3} \mathrm{H}\right]$ DPPC ether-labeled human VLDL containing 7.5-9.5 $\times 10^{5} \mathrm{cpm}$. The transfer of phospholipids from VLDL into HDL was measured as described in Methods. Results are shown for wild-type mice $(n=4)$ and PLTP $^{-/-}$mice $(n=5)$. FC, free cholesterol; $H D L$, high-density lipoprotein; $P C$, phosphatidylcholine; $P E$, phosphatidyl ethanolamine; PI, phosphatidyl inositol; PLTP KO, PLTP knockout mice; SM, sphingomyelin; VLDL, very-low-density lipoprotein; $W t$, wild-type.

The distribution of lipids was also determined by FPLC of pooled plasma samples (Fig. 4). This confirmed that HDL phospholipid, cholesteryl ester, and free cholesterol were dramatically decreased in $\mathrm{PLTP}^{-/}$ mice compared with wild-type and $\mathrm{PLTP}^{+/-}$mice. Assessment of apolipoprotein composition of centrifugally isolated lipoproteins by reducing sodium

Table 2

Distribution of mouse apo Al among pre- $\beta-\mathrm{HDL}$ and $\alpha-\mathrm{HDL}$ in PLTP knockout and wild-type mice

\begin{tabular}{lcccc}
\cline { 3 - 4 } Mice & Diet & Apo Al & $\begin{array}{c}\text { pre- } \beta-\mathrm{HDL} \\
(\mathrm{mg} / \mathrm{dl})\end{array}$ & $\alpha-\mathrm{HDL}$ \\
& & & $3.5 \pm 2.4$ & $68 \pm 8$ \\
$+/+$ & Chow & $68 \pm 10$ & $0.6 \pm 0.3^{\mathrm{B}}$ & $9 \pm 7^{\mathrm{A}}$ \\
$-/-$ & Chow & $10 \pm 8^{\mathrm{A}}$ & $0.9 \pm 2.4$ & $174 \pm 55$ \\
$+/+$ & Western & $180 \pm 28$ & $5.9 \pm 2.4$ & $28 \pm 22^{\mathrm{A}}$ \\
$-/-$ & Western & $29 \pm 22^{\mathrm{A}}$ & $1.2 \pm 0.9^{\mathrm{B}}$ & 28
\end{tabular}

The determination of the proportion of pre- $\beta-\mathrm{HDL}$ and $\alpha-\mathrm{HDL}$ species in the PLTP knockout and wild-type mice was described previously (23). Apo Al was measured by ELISA as described (23). ${ }^{A} P<0.001,{ }^{B} P<0.05, n=5$.

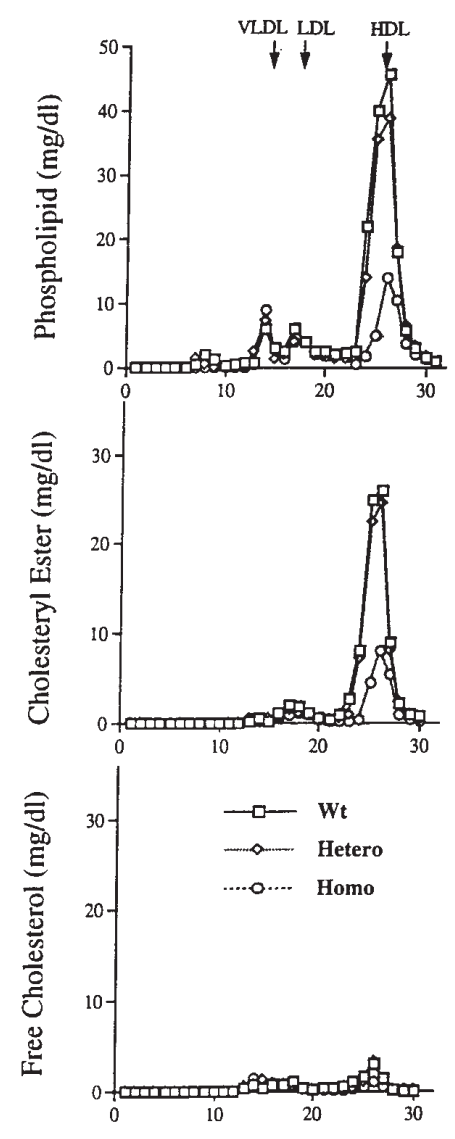

Fraction

\section{Figure 4}

Plasma lipoprotein analysis by FPLC in chow-fed male mice. A 200- $\mu$ l aliquot of pooled plasma (from 6-10 animals) was loaded onto a Sepharose $6 \mathrm{~B}$ column and eluted with $50 \mathrm{mM}$ Tris, $0.15 \mathrm{M} \mathrm{NaCl}(\mathrm{pH} 7.5)$. An aliquot of each fraction was used for the determination of free cholesterol, cholesteryl ester, and phospholipid. The concentration in each fraction is expressed as mg/dl mouse plasma. Chow-fed female mice had a similar lipid distribution profile. FPLC, fast protein liquid chromatography.

dodecyl sulfate-polyacrylamide gel electrophoresis (SDS-PAGE) revealed a marked decrease of apo AI and apo AIV in HDL (Fig. 5). A profound decrease of plasma apo AI level was also shown by enzyme-linked immunosorbent assay (ELISA) (Table 2). Apparent slight changes in apo B levels were not significant (Fig. 5 and Table 1). The distribution of mouse apo AI among pre- $\beta$-HDL and $\alpha$-HDL in $\mathrm{PLTP}^{-/-}$and wildtype was determined using an antibody specific for murine apo AI. As shown in Table 2 , both pre- $\beta$-HDL and $\alpha$-HDL were dramatically decreased in $\mathrm{PLTP}^{-/-}$ mice compared with wild-type mice. However, the ratio of pre- $\beta$-HDL to $\alpha$-HDL was not changed.

Plasma lipoprotein analysis: high-fat/high-cholesterol diet. To further evaluate the changes in plasma lipoprotein levels, 3-month-old mice were challenged with a high-saturated fat diet (20\% hydrogenated coconut oil, $0.15 \%$ cholesterol) for two weeks. In response to this diet, HDL phospholipid and cholesterol were markedly decreased in PLTP $^{-}-$mice. However, there was an increase in VLDL and LDL phospholipid and choles- 
Table 3

Plasma lipid and lipoprotein concentrations in wild-type (+/+), $\mathrm{PLTP}^{+/-}$, and PLTP-/- mice on a high-fat diet

\begin{tabular}{|c|c|c|c|c|c|c|c|c|c|c|}
\hline & PL & HDL-PL & $\begin{array}{l}\text { VLDL/ } \\
\text { LDL-PL }\end{array}$ & Cholesterol & $\begin{array}{l}\text { HDL-CE } \\
(\mathrm{mg} / \mathrm{dl})\end{array}$ & HDL-FC & $\begin{array}{l}\text { VLDL/ } \\
\text { LDL-CE }\end{array}$ & V/LDL-FC & apo B & TG \\
\hline \multicolumn{11}{|c|}{ Male } \\
\hline $\begin{array}{l}+/+ \\
+/- \\
-/-\end{array}$ & $\begin{array}{l}235 \pm 29 \\
222 \pm 39 \\
210 \pm 36\end{array}$ & $\begin{aligned} 164 & \pm 21 \\
155 & \pm 28 \\
60 & \pm 16^{A}\end{aligned}$ & $\begin{array}{c}47 \pm 11 \\
50 \pm 10 \\
150 \pm 28^{A}\end{array}$ & $\begin{array}{l}158 \pm 43 \\
164 \pm 37 \\
152 \pm 34\end{array}$ & $\begin{array}{l}99 \pm 17 \\
96 \pm 16 \\
28 \pm 8^{A}\end{array}$ & $\begin{array}{c}15 \pm 5 \\
15 \pm 7 \\
8 \pm 3^{\mathrm{A}}\end{array}$ & $\begin{array}{l}26 \pm 7 \\
33 \pm 11 \\
46 \pm 16^{A}\end{array}$ & $\begin{array}{l}17 \pm 5 \\
20 \pm 7 \\
69 \pm 4^{\mathrm{A}}\end{array}$ & $\begin{array}{l}71 \pm 20 \\
70 \pm 17 \\
66 \pm 19\end{array}$ & $\begin{array}{l}160 \pm 41 \\
152 \pm 61 \\
156 \pm 56\end{array}$ \\
\hline \multicolumn{11}{|c|}{ Female } \\
\hline $\begin{array}{l}+/+ \\
+/- \\
-/-\end{array}$ & $\begin{array}{l}190 \pm 33 \\
181 \pm 26 \\
221 \pm 31\end{array}$ & $\begin{aligned} 133 & \pm 31 \\
126 & \pm 27 \\
66 & \pm 18^{A}\end{aligned}$ & $\begin{array}{c}57 \pm 12 \\
55 \pm 15 \\
155 \pm 12^{\mathrm{A}}\end{array}$ & $\begin{array}{l}145 \pm 22 \\
148 \pm 34 \\
162 \pm 29\end{array}$ & $\begin{array}{l}93 \pm 15 \\
91 \pm 21 \\
24 \pm 9^{A}\end{array}$ & $\begin{array}{c}13 \pm 3 \\
12 \pm 4 \\
7 \pm 2^{A}\end{array}$ & $\begin{array}{l}24 \pm 6 \\
26 \pm 4 \\
54 \pm 8^{A}\end{array}$ & $\begin{array}{l}16 \pm 5 \\
19 \pm 8 \\
76 \pm 11^{\mathrm{A}}\end{array}$ & $\begin{array}{l}70 \pm 28 \\
69 \pm 15 \\
66 \pm 19\end{array}$ & $\begin{array}{l}151 \pm 66 \\
139 \pm 44 \\
144 \pm 51\end{array}$ \\
\hline
\end{tabular}

HDL was separated from VLDL/LDL by precipitation with HDL cholesterol reagent. The total cholesterol, phospholipid, and triglyceride concentrations were determined by enzymatic methods. Apo B, including apo B48 and apo B100, was measured by ELISA as described. APLTP knockout mice versus wild-type mice, $P<0.001$. Values are mean \pm SD based on analyses of individual mouse plasma and represent of 6-10 animals per group.

terol (3.1- and 2.4-fold, respectively) in $\mathrm{PLTP}^{-/-}$mice compared with wild-type mice (Table 3 ). The distribution of lipids among the lipoprotein fractions was determined by FPLC (Fig. 6). This confirmed the decrease in HDL lipids in PLTP $^{-/-}$mice and revealed a marked increase in phospholipid and free cholesterol in VLDL, and in a shoulder of the VLDL peak merging into the LDL region. There was also an increase in cholesteryl ester in the VLDL, but this was less pronounced than the free cholesterol and phospholipid increases in the IDL/LDL region, suggesting accumulation of surface components (phospholipid, free cholesterol) of TRL in the IDL/LDL. Consistent with this suggestion, plasma apo B analysis (Table 3) and SDS-PAGE of the isolated lipoprotein fraction showed no increase in apo $\mathrm{B}$ in the VLDL/LDL fraction (Fig. 7). These results suggest that the increased flux of lipid through the plasma compartment on the high-fat/high-cholesterol diet leads to accumulation of phospholipid- and free cholesterol-enriched surface components of TRL in the IDL/LDL fraction in PLTP $^{-/-}$mice.

Negative-stain electron microscopy of plasma lipoproteins. To assess the presence of such lamellar particles, negative-stain electron microscopy was carried out on lipoproteins isolated by FPLC in mice fed the high-fat diet. This revealed vesicular particles in the IDL/LDL fraction of $\mathrm{PLTP}^{-/}$mice (Fig. 8c, curved arrow) that were absent in wild-type mice (Fig. 8d). VLDL and HDL contained lipoproteins of typical spherical morphology (not shown). Similar studies on centrifugally isolated lipoproteins showed that vesicular particles were found in the HDL fraction in $\mathrm{PLTP}^{-/-}$mice (Fig. $8 a$ ) but not in wild-type mice (Fig. $8 b$ ), while VLDL and LDL contained spherical particles (data not shown). Thus, the vesicular lipoproteins, while eluting in the IDL/LDL region by FPLC, are of sufficiently high density to sink into the HDL fraction. This may reflect the presence of highly saturated phospholipids on the coconut oil diet.

Plasma cholesterol esterification and LCAT activity. HDL phospholipid is substrate for the cholesterol-esterifying enzyme lecithin cholesterol acyltransferase (LCAT). Thus, we examined plasma LCAT activity (a measurement of LCAT mass) and endogenous plasma cholesteryl ester formation in $\mathrm{PLTP}^{-/-}$and wild-type mice on chow and high-fat diets. There were no significant differences in LCAT activity or endogenous cholesterol esterification rate (Table 4).

\section{Discussion}

Our studies reveal an essential role of PLTP in plasma lipoprotein metabolism. The ability of plasma to stimulate transfer of all of the major plasma phospholipids (PC, SM, PI, and PE) and free cholesterol from vesicles into HDL was almost abolished in PLTP knockout mice, indicating a unique contribution of the PLTP gene to these activities in the mouse. In vitro assays of PLTP activity always show significant background, reflecting spontaneous phospholipid transfer in the absence of plasma (15). Thus, it was surprising that the rapid in vivo transfer of VLDL phospholipid into HDL was abolished in PLTP knockout mice (Fig. 3), indicating that there is little spontaneous transfer of VLDL phospholipid into HDL. Although it has long been suspected that the transfer of phospholipid and cholesterol from TRL plays a role in the maintenance of HDL levels (3), the magnitude of this contribution has never been quantified. The most dramatic aspect of the phenotype of homozygous PLTP knockout mice was a marked $60 \%-70 \%$ reduction in HDL levels, with major reductions in HDL phospholipid, free cholesterol, choles-

\section{Table 4}

LCAT activity in plasma and endogenous CE formation in plasma of wildtype and PLTP knockout mice

\begin{tabular}{cccc}
\cline { 2 - 3 } Mice & Diet & $\begin{array}{c}\text { LCAT activity } \\
(\mathrm{nmol} / \mathrm{ml} / \mathrm{h})\end{array}$ & $\begin{array}{c}\text { Plasma CE formation } \\
(\mathrm{nmol} / \mathrm{ml} / \mathrm{h})\end{array}$ \\
$+/+$ & Chow & $76 \pm 3$ & $39 \pm 8$ \\
$-/-$ & Chow & $73 \pm 9$ & $34 \pm 10$ \\
$+/+$ & Western & $74 \pm 16$ & $44 \pm 12$ \\
$-/-$ & Western & $71 \pm 7$ & $40 \pm 7$ \\
\hline
\end{tabular}

ALCAT activity was determined by the apo Al discoidal substrate assay, equivalent to LCAT mass. ${ }^{B}$ Plasma CE formation was determined as follows: fresh plasma from mice was incubated at $37^{\circ} \mathrm{C}$ for $1 \mathrm{~h}$. Total and free cholesterol were determined, and CE formation was expressed as nanomole decrease of free cholesterol per milliliter of plasma per hour. CE, cholesteryl ester; LCAT, lecithin cholesterol acyltransferase. 


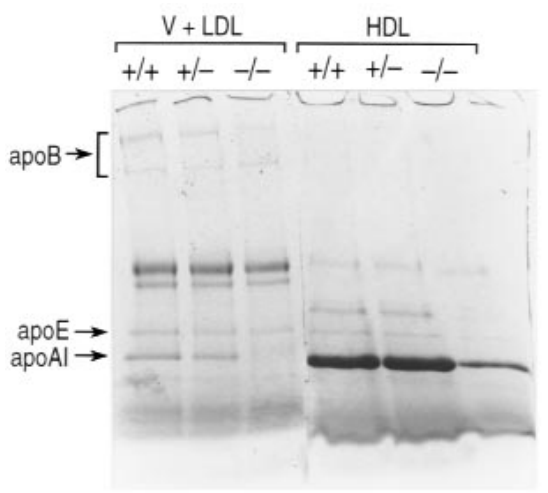

Figure 5

SDS-PAGE analysis of apolipoproteins from ultracentrifugally isolated plasma lipoproteins (chow diet). Plasma HDL (density = $1.063-1.21 \mathrm{~g} / \mathrm{ml}$ ) and VLDL + LDL (density $=1.006-1.063 \mathrm{~g} / \mathrm{ml}$ ) were separated by preparative ultracentrifugation as described. SDS-PAGE was performed on $3 \%-20 \%$ SDS-polyacrylamide gradient gel, and the apolipoproteins were stained by Coomassie brilliant blue as described.

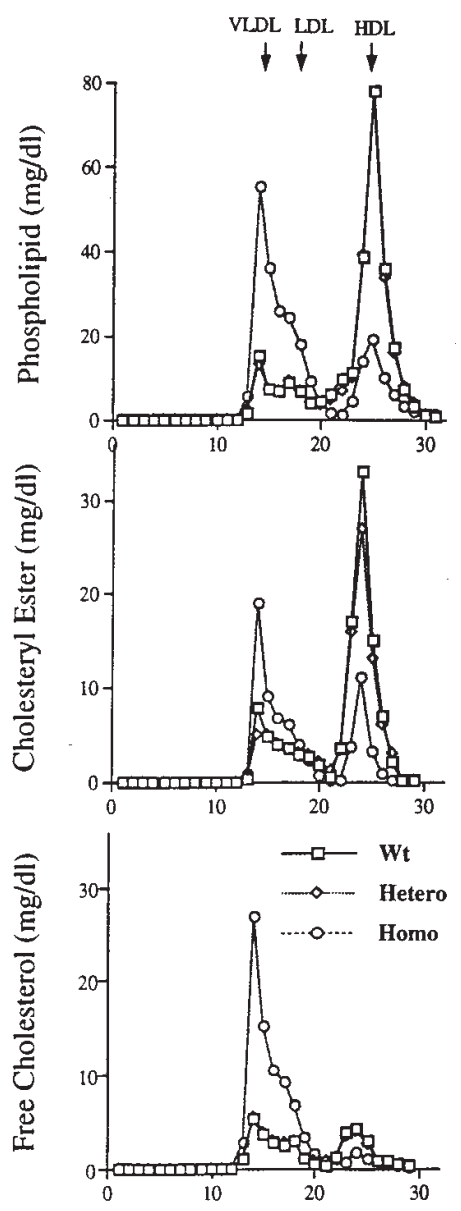

Fraction

\section{Figure 6}

Plasma lipoprotein analysis by FPLC (male mice, high-fat diet). An aliquot $(200 \mu \mathrm{l})$ of pooled plasma $(6-10$ mice) was analyzed as described in the Fig. 4 legend. The concentration in each fraction is expressed as mg/dl mouse plasma. Female mice fed the high-fat diet had a similar lipid distribution profile. teryl ester, and apo AI. Thus, in the mouse, the transfer of phospholipid and free cholesterol from TRL into HDL is uniquely mediated by PLTP and plays a major role in the determination of levels of all of the principal components of HDL.

The reduced HDL levels in $\mathrm{PLTP}^{-/-}$mice may reflect both decreased transfer of surface components from TRL into HDL and altered stability of HDL particles. It is likely that PLTP has binding sites for phospholipid (30) and mediates phospholipid transfer by a carrier mechanism. PLTP may also have the capacity to bind and transfer free cholesterol (31). Thus, it is likely that a block in the transfer of phospholipid and free cholesterol leads to depletion of these components in HDL. Apo AI is secreted in association with TRL, and the transfer of apo AI from TRL into HDL may depend on the transfer of phospholipid and free cholesterol. In addition to direct effects of decreased transfer, it is likely that the stability of HDL particles is altered in PLTP knockout mice. The lipidation of protein-rich nascent HDL particles, dependent on PLTP activity, may lead to stabilization of these particles. Consistent with this suggestion, preliminary studies indicate hypercatabolism of HDL PC and apo AI in PLTP $^{-/-}$mice (Jiang, X.-c., and Tall, A.R., unpublished observations).

Interestingly, the heterozygote knockout mouse, while having a dose-related depletion of plasma phospholipid transfer activity, did not display significant changes in plasma lipoprotein levels. This suggests that normal plasma PLTP activity is more than sufficient to provide components for HDL. Thus, the transgenic overexpression of PLTP only produced a high-HDL phenotype when crossed with apo A-I trangenic mice, where the excessive production of HDL protein may have outstripped the ability of PLTP to stimulate lipidation of nascent HDL (23). In mice with massive overexpression (20- to 40-fold) of PLTP by adenovirus injection $(24,25)$, it is possible that low HDL reflects destabilization of HDL particles, owing to very high levels of surface active PLTP. Several lines of evidence have shown a role of PLTP in stimulating the formation of pre- $\beta$-HDL particles $(23$, $24,32)$. The presence of much lower pre- $\beta$-HDL in PLTP knockout mice (17\% of that in wild-type) (Table 2 ) is consistent with a role of this activity in pre- $\beta$ HDL formation. However, as opposed to overexpression experiments, the loss of PLTP activity in PLTP knockout mice did not result in disproportionate changes in pre- $\beta$-HDL, suggesting a role of other factors in determining the ratio of pre $\beta / \alpha$ HDL.

The high expression of PLTP in the lung, and its induction by hypoxia in alveolar type II cells (33), has suggested that PLTP might play a role in pulmonary function, for example, by helping to provide phospholipid from circulating lipoproteins for pulmonary surfactant production. The lack of an overt lung phenotype in the PLTP knockout mice indicates that it does not play an essential role. Also, preliminary examination of lung sections, stained with hemotoxylin and eosin, showed no gross abnormality (Jiang, X.-c., and Tall, A.R., unpublished observations). It is well known 
Figure 7

SDS-PAGE analysis of apolipoproteins from ultracentrifugally isolated plasma lipoproteins (high-fat diet). See Fig. 5 legend for detail. The molecular weights of markers are (from top to bottom) $98 \mathrm{kDa}, 67 \mathrm{kDa}$, $45 \mathrm{kDa}, 30 \mathrm{kDa}, 20 \mathrm{kDa}$, and $14 \mathrm{kDa}$.

that the alveolar type II cell has a great capacity to synthesize PC, by induction of cytidylyltransferase activity (34). This ability could compensate for a possible reduction in uptake of lipoprotein PC.

On both chow and high-fat diets, the most dramatic feature of the PLTP knockout mouse phenotype was the reduced HDL levels. However, on the high-fat diet, this was associated with an accumulation of lipids in the VLDL and LDL fraction. This occurred without elevation of plasma apo B or triglyceride levels, and presumably reflects the accumulation of phospholipid- and free cholesterol-rich surface components of TRL. Vesicular lipoproteins were identified by negative-stain electron microscopy in the LDL region (Fig. 6). These may appear on the high-fat diet because of increased flux of TRL, leading to enhanced accumulation of surface components. Unexpectedly, there was also some accumulation of cholesteryl ester, especially in VLDL (Fig.6). We carried out preliminary turnover studies with VLDL carrying radiolabeled cholesteryl ester to test the possibility that in vivo PLTP might play a role in transferring VLDL cho-

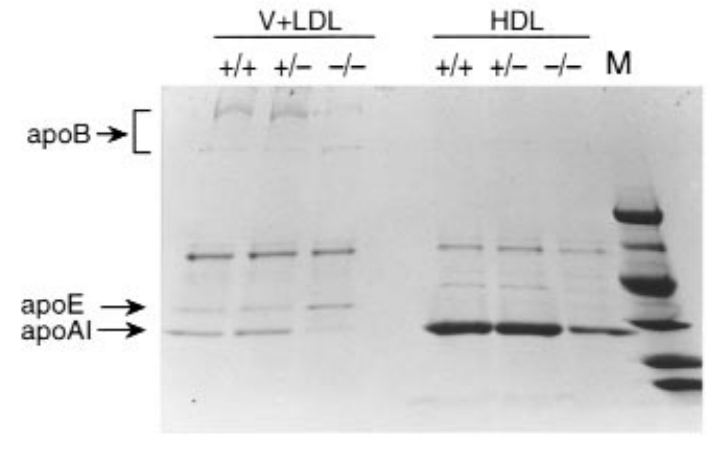

lesteryl ester into HDL; however, there was no significant transfer in either wild-type or PLTP ${ }^{-/-}$mice (Jiang,X.-c., and Tall, A.R., unpublished observations). One possible explanation is that LCAT activity is diverted from HDL into VLDL in PLTP $-/$ mice on the high-fat diet. Another is that $\mathrm{PLTP}^{-/-}$mice have a subtle defect in clearance of VLDL remnants.

The phenotype of the PLTP knockout mouse (i.e., low HDL and high levels of non-HDL cholesterol) is usually associated with increased propensity to atherosclerosis. However, the increased LDL on the atherogenic diet predominantly reflects the presence of vesicular lipoproteins, which may have antiatherogenic properties (35). Preliminary analysis indicates that the vesicular lipoproteins are enriched in apo AIV (Jiang, X.-c., et al., unpublished observations) and thus may resemble the particles accumulating in apo E knockout/hepatic lipase knockout mice, which appear to have antiatherogenic properties (36). The impact of the PLTP knockout on atherogenesis will be tested by crossing with induced mutant strains with increased atherosclerosis susceptibility.

\section{Figure 8}

Negative-stain electron microscopy of lipoprotein preparations from wild-type and PLTP knockout mice. Lipoprotein preparations from PLTP knockout ( $\boldsymbol{a}$ and $\boldsymbol{c}$ ) or wild-type mice ( $\boldsymbol{b}$ and $\boldsymbol{d}$ ), isolated by ultracentrifugation $($ density $=1.125-1.21 \mathrm{~g} / \mathrm{ml})(a$ and $b$ ), or FPLC (IDL/LDL size range) ( $c$ and $d$ ) are shown. In $a$, curved arrows represent vesicles, short arrows represent HDL. In $c$, curved arrows represent vesicles, short arrows represent LDL. Both $a$ and $b$ have the same magnification $(\times 200,000) ; c$ and $d$ also have the same magnification $(\times 100,000)$.
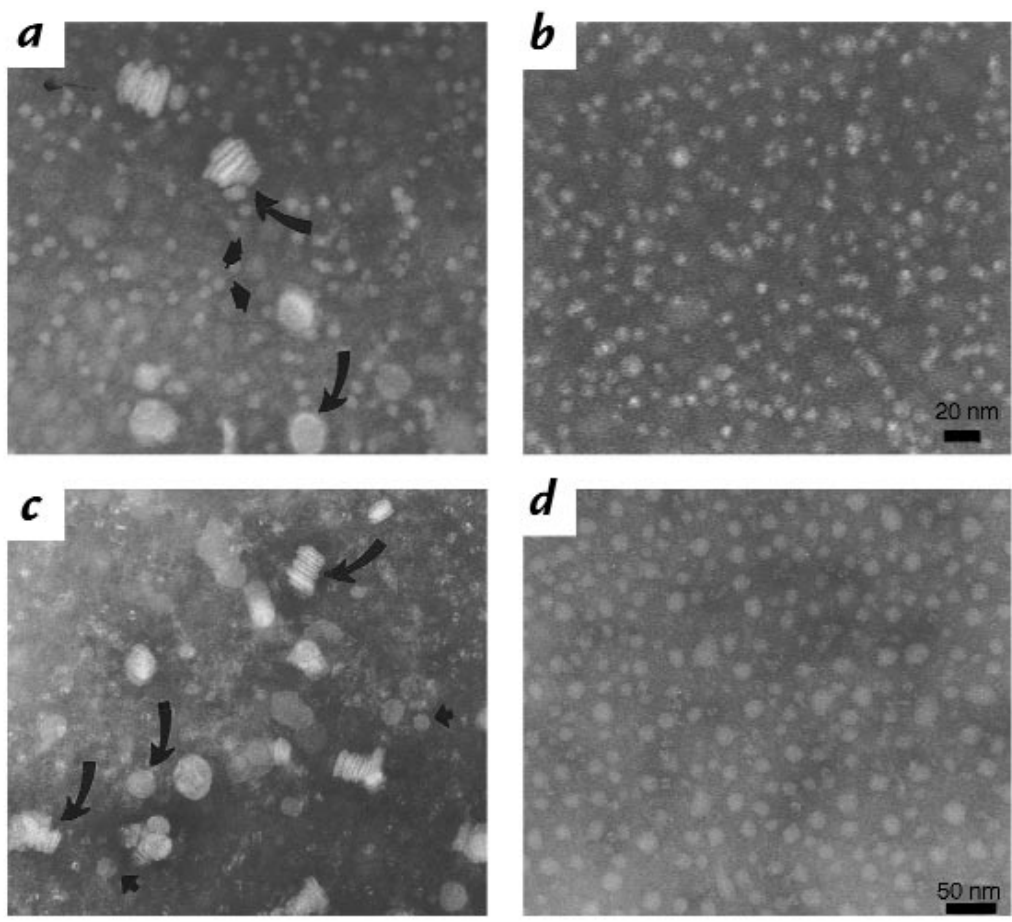


\section{Acknowledgments}

We thank Jan Breslow for guidance and support, and Lori Royer for the apo AI and apo B measurements. This work was supported by National Institutes of Health grant HL-54591.

1. Rhoads, G.G., Gulbrandsen, C.L., and Kagan, A. 1976. Serum lipoproteins and coronary heart disease in a population study of Hawaii Japanese men. N. Engl. J. Med. 294:293-298.

2. Havel, R.J., Kane, J.P., and Kashyap, M.L. 1973. Interchange of apolipoproteins between chylomicrons and high density lipoproteins during alimentary lipemia in man. J. Clin. Invest. 52:32-38.

3. Mjos, O.D., Faergeman, O., Hamilton, R.L., and Havel, R.L. 1975. Characterization of remnants produced during the metabolism of triglyceride-rich lipoproteins of blood plasma and intestinal lymph in the rat. J. Clin. Invest. 56:603-615.

4. Chajek, T., and Eisenberg, S. 1978. Very low density lipoprotein. Metabolism of phospholipids, cholesterol, and apolipoprotein $\mathrm{C}$ in the isolated perfused rat heart. J. Clin. Invest. 61:1654-1665.

5. Patsch, J.R., Gotto, A.M., Jr., Olivercrona, T., and Eisenberg, S. 1978. Formation of high density lipoprotein 2-like particles during lipolysis of very low density lipoproteins in vitro. Proc. Natl. Acad. Sci. USA. 75:4519-4523.

6. Tall, A.R., Green, P.H.R., Glickman, R.M., and Riley, J.W. 1979. Metabolic fate of chylomicron phospholipids and apoproteins in the rat. J. Clin. Invest. 64:977-989.

7. Redgrave, T.G., and Small, D.M. 1979. Quantitation of the transfer of surface phospholipid of chylomicrons to the high density lipoprotein fraction during the catabolism of chylomicrons in the rat.J. Clin. Invest. 64:162-171.

8. Green, P.H.R., Tall, A.R., and Glickman, R.M. 1978. Rat intestine secretes discoidal high density lipoprotein. J. Clin. Invest. 61:528-534.

9. Hamilton, R.L., Williams, M.C., Fielding, C.J., and Havel, R.J. 1976. Discoidal bilayer structure of nascent high density lipoproteins from perfused rat liver. J. Clin. Invest. 58:667-680.

10. Forte, T.M., Bielicki, J.K., Goth-Goldstein, R., Selmek, J., and McCall, M.R. 1995. Recruitment of cell phospholipids and cholesterol by apolipoproteins A-II and A-I: formation of nascent apolipoprotein-specific HDL that differ in size phospholipid composition, and reactivity with LCAT. J. Lipid Res. 36:148-157.

11. Hamilton, R.L., Moorehouse, A., and Havel, R.J. 1998. Isolation and properties of nascent lipoproteins from highly purified rat hepatocytic Golgi fractions. J. Lipid Res. 32:529-543.

12. Tall, A.R., and Small, D.M. 1978. Plasma high density lipoproteins. $N$. Engl.J. Med. 30:1232-1236.

13. Glomset, J.A., and Norum, K.R. 1973. The metabolic role of lecithin:cholesterol acyltransferase: perspectives from pathology. Adv. Lipid Res. 11:1-65.

14. Jonas, A. 1979. Interaction of bovine serum high density lipoprotein with mixed vesicles of phosphatidylcholine and cholesterol. J. Lipid Res. 20:817-824.

15. Tall, A.R., and Green, P.H.R. 1981. Incorporation of phosphatidylcholine into spherical and discoidal lipoproteins during incubation of egg phosphatidylcholine vesicles with isolated high density lipoproteins or with plasma. J. Biol. Chem. 256:2035-2044.

16. Tall, A.R., Krumholz, S., Olivercona, T., and Deckelbaum, R.J. 1985. Plasma phospholipid transfer protein enhances transfer and exchange of phosphatidylcholine between VLDL and HDL during lipolysis. J. Lipid Res. 26:842-852.

17. Tall, A.R., Abreu, E., and Shuman, J. 1983. Separation of a plasma phospholipid transfer protein from cholesteryl ester/phospholipid exchange protein. J. Biol. Chem. 258:2174-2180.

18. Tollefson, J.H., Ravnik, S., and Albers, J.J. 1988. Isolation and characterization of a phospholipid transfer protein (LTP-II) from human plasma. J. Lipid Res. 29:1593-1601.

19. Day, J.R., et al. 1994. Complete cDNA encoding human phospholipid transfer protein from human endothelial cells. J. Biol. Chem. 269:9388-9391.

20. Brown, M., Hesler, C., and Tall, A.R. 1990. Plasma enzymes and transfer proteins in cholesterol metabolism. Curr. Opin. Lipidol. 1:122-127.

21. Yu, B., Hailman, E., and Wright, S.D. 1997. Lipopolysaccharide binding protein and soluble CD14 catalyze exchange of phospholipids. J. Clin. Invest. 99:315-324.

22. Jiang, X.-c., and Bruce, C. 1995. Regulation of murine plasma phospholipid transfer protein activity and mRNA levels by lipopolysaccharide and high cholesterol diet. J. Biol. Chem. 270:17133-17138.

23. Jiang, X.-c., et al. 1996. Increased pre $\beta$-high density lipoprotein, apolipoprotein AI, and phospholipid in mice expressing the human phospholipid transfer protein and human apolipoprotein AI transgenes. J. Clin. Invest. 96:2373-2380.

24. Foger, B., et al. 1997. Plasma phospholipid transfer protein-adenovirusmediated overexpression in mice leads to decreased plasma high density lipoprotein (HDL) and enhanced hepatic uptake of phospholipids and cholesteryl esters from HDL. J. Biol. Chem. 272:27393-27400.

25. Ehnholm, S., et al. 1998. Adenovirus mediated overexpression of human phospholipid transfer protein alters plasma HDL levels in mice. J. Lipid Res. 39:1248-1253.

26. Robertson, E.J. 1987. Embryo-derived stem cell lines. In Teratocarcinomas and embryonic stem cells: a practical approach. E.J. Robertson, editor. IRL Press. Oxford, United Kingdom. 71-112.

27. Bradley, A. 1987. Production and analysis of chimeric mice. In Teratocarcinomas and embryonic stem cells: a practical approach. E.J. Robertson, editor. IRL Press. Oxford, United Kingdom. 113-151.

28. Jeong, T.S., et al. 1998. Increased sphingomyelin content of plasma lipoproteins in apolipoprotein E knockout mice reflects combined production and catabolic defects and enhances reactivity with mammalian sphingomyelinase. J. Clin. Invest. 101:905-912.

29. Jiang, X.-c., et al. 1993. Down-regulation of mRNA for the low density lipoprotein receptor in transgenic mice containing the gene for human cholesteryl ester transfer protein. J. Biol. Chem. 268:27406-27412.

30. Beamer, L.J., Carroll, S.F., and Eisenberg, D. 1997. Crystal structure of human BPI and two bound phospholipids at 2.4 angstrom resolution. Science. 276:1861-1864.

31. Connolly, D.T., et al. 1996. Physical and kinetic characterization of recombinant human cholesteryl ester transfer protein. Biochem. J. 320:39-47.

32. Lusa, S., Jauhiainen, M., Metso, J., Somerharju, P., and Ehnholm, C. 1996. The mechanism of human plasma phospholipid transfer proteininduced enlargement of high-density lipoprotein particles: evidence for particle fusion. Biochem. J. 313:275-282.

33. Jiang, X.-c., et al. 1998. Expression of plasma phospholipid transfer protein mRNA in normal and emphysematous lungs and regulation by hypoxia. J. Biol. Chem. 273:15714-15718.

34. Rooney, S.A. 1985. State of art: the surfactant system and lung phospholipid biochemistry. Am. Rev. Respir. Dis. 131:439-460.

35. Williams, K.J., Tall, A.R., Bisgaier, C., and Brocia, R. 1987. Phospholipid liposomes acquire apolipoprotein $\mathrm{E}$ in atherogenic plasma and block cholesterol loading of cultured macrophages. J. Clin. Invest. 79: 1466-1472.

36. Bergeron, B., et al. 1998. Lamellar lipoproteins uniquely contribute to hyperlipidemia in mice doubly deficient in apolipoprotein $\mathrm{E}$ and hepatic lipase. Proc. Natl. Acad. Sci. USA. 95:15647-15652. 